\section{COP 06}

CANCER IN ADVANCED AGE - REASONABLE AIMED RADIOTHERAPY R. Sauer

The field of problems concerning "cancer in advanced age" or "the senile cancer patient" may not only be discussed from the medical point or view. It also includes humanitarian, moral, social-ethical and social-political aspects. In addition to treatability also the therapeutic claim and the need of treatment have to be examined.

The medical indications for tumor therapy and for the relevant diagnostic procedures are defined. They depend on tumor type, tumor stage, age-related tumor biology and the physical conditions of the patient. That an old individual presents with a limited tolerance for all medical interventions, is considered.

In general, the direct cause of a tumor patient's death is caused by general intercurrent problems and not related to the tumor directly. An oncologic therapy does not prolong dying, but can relieve by palliating the disease. So it complies with the medical commission.

It is true that the ethical and moral imponderables in connection with the indication of treatment are especially focussed to the old patient, however, they have to be managed in each period of life. A young man claims for a dignified dying and an opportune death in like manner. For young and old the same measures have to be applied. They cannot be determined by the physician alone.

\section{COP 08}

THE OPERATIVE TREATMENT OF GASTRIC CANCER IN ELDERLY AND OLD PATIENTS.

H. Stöltzing, C. Pohl, K. Thon and H.-D. Röher

The WHO-recommendation (1963) defines patients between 65-75 years old as elderly and above 75

as old. Indications for surgery must be carefully weighed up in these patients, due to greater risks of multimorbidity(H.-D. Röher, Chirurg 55 , $75,1984)$. In addition to the usual risk assessment criteria, mortality figures for the particular operative procedure from the hospital's own collective must be considered. This is especially true for gastric cancer patients, where a number of curative or palliative measures exist. Patients: 195 patients with gastric cancer were operated on between 1/1/79-30/6/85. Half of these patients were older than $65 y$ (29\%"elder$1 y, 20 \%$ "old"). The overall operative mortality (30 days) was $10.7 \%$, the resection rate was $74 \%$ (64 partial, 81 total gastrectomies). Mortality rates after palliative methods or partial gastric resection were almost identical, but differed from those after total gastrectomy. Total gastrectomy exhibited mortalities of $11 \%$ (pat. $<65$ y), $23 \%(65-75$ y) and $40 \%(>75$ y). Mortality after palliative measures or partial gastrectomy was due to general complications, e.g. cardiac or respiratory failure. However, after total gastrectomy operative complications, e.g. anastomotic insufficiency were more importantant. Conclusions: Although successful major surgery can now be performed in elderly and old patients, the increased rate of complications and mortality should remind the surgeon to exercise caution. In biologically old patients with gastric cancer a reasonable choice of treatment is more important than the performance of the technically possible.

\section{$\operatorname{COP} 09$}

\section{COP 07}

MAIN ASPEKTS OF PSYCHO-SOCIAL CONSELING WITH EIDERLY CANCER PATIFNIS K. Röttger, A. Boeger, W. Saverwein, M. Rieger-Weber, B. Witte

Cancer is mainly a sidkness of the elderly. The number of people over 60 years of age will increase from 11,7 million (1980) to 12,1 million (1990) and to 13,4 million (2005) (Haag,G. Entwicklungstendenzen der Altenhilfe, Orkologie 2,84). The psychic and social aspects of cancer are different for the older generation. Between 01.01.84 and 30.09.85 contacts were made with 1324 patients. 23,4 \% of these were more then 60 years of age. According to the experience of the Psycho-Social Help Center of the University Clinic Essen, the work with these patients entails five main problems: 1 . The demand for a dignified life is foremcst in the minds of older patients. The readiness, to accept an increased life span at the cost of chronic suffering, is not so high. 2. The coinciding professional retirement of the patient has already resulted in a loss of social function. The patient is therefore already faced with a feeling of lack of purpose which can lead to latent nonspecific dissatisfaction. 3. Retírenent results in a worsening of the financial situation of many patients. This el iminates therefore an important requirement for an independent and dignified life. 4. The family and social relationships are reouced in many cases: The moving out of the children, the loss of "the partner. This reduces in turn the possibility of social, emotional and personal contact and help. 5. Providing these patients with appropriate homes, in wich they can remain or be treated for as long as possible, is important. Comprehensive psycho-social counseling with the patients already during the first stages of their illnes would therefore be aptimal. Close cooperation with the attending clinicians is mandatory. such a counseling should respect the patients desire for autanomy and strengthen the intra family relationships. Ambulant supportive service should be utilized to prevent admission into a nursing home. This results not only in an inproved quality of life for the patients but also reduces costs. Services which can be offered or arranged by a osycho-sucial Help Center include: Counceling; home nursing care; provision of technical aids; medical rehabilitation; gymastics, sports and physiotherapy; pedicure; cleaning, laundry and meal home service; recreational activities; self-help-groups; financial support; finding hames suitable for elderly and handicapt. (Rustemeyer, J.: Rohabilitation u. Alter, Med. Welt 33,(1982)

Psychosoziale Beratungstelle des Universitätsklinikums, D-4300 Essen AGE

W. Sasse, A. Holzgreve and $H$. Bünte

In view of controversial theories about the age-related behavior of tumors we attempted to clarify the problem by analysing data from the literature with the aid of an integrating method of evaluation. A total of 302668 cases reported in the literature were included. Our results led to a revision of the concept of lower malignancy in old-age cancer, which appears no longer justified. Consequently, the surgeon will no longer feel bound to reduce the radicality of resection in older tumor patients. The generally revised approach to cancer surgery has resulted in a considerably improved survival of older tumor patients. Gastric carcinoma may serve as an example for tumor surcery in the elderly and its rationale. Of 853 patients who received surrical treatment for stomach cancer between 1974 - 1984, 192 were over 70 , i.e. $22,5 \frac{\circ}{3}$. The rate of resections in patients over 70 was $47,9 \%$, in patients under 70 , 60,7 \%. Intraoperative lethality rates being approximately the same in both groups. The five-year survival rates differed only by $5 \%$ It was $48 \%$ in patients under 70 and $43 \%$ in those over 70 years. A marked difference, however, is manifested after the 7 th year of survival, when the higher mortality rates of older

Abteilung für Chirurgische onkologie der Chirurgischen Klinik und Poliklinik der Westfälischen Wilhelms-Universität Münster Jungeblodtplatz 1, D-4400 Münster
SURGICAL TREATMENT OF GASTRIC CARCINOMA IN OLD people in general are at play. 